\title{
Characterization of Solid Oxide Fuel Cells with LSCF-SDC Composite Cathodes
}

\author{
Gianfranco DiGiuseppe $(\mathbb{D}$ and Venkatesh Boddapati \\ Department of Mechanical Engineering, Kettering University, 1700 University Avenue, Flint, MI 48504-4898, USA \\ Correspondence should be addressed to Gianfranco DiGiuseppe; gdigiuse@kettering.edu
}

Received 7 March 2018; Accepted 2 May 2018; Published 3 June 2018

Academic Editor: Mohamed Benghanem

Copyright (C) 2018 Gianfranco DiGiuseppe and Venkatesh Boddapati. This is an open access article distributed under the Creative Commons Attribution License, which permits unrestricted use, distribution, and reproduction in any medium, provided the original work is properly cited.

\begin{abstract}
This paper reports the study of an anode-supported SOFC cell containing an LSCF-SDC composite cathode. The SOFC cell was tested at different temperatures and reactant flow rates. After testing, the cell was sectioned and characterized using SEM/EDS. Such analysis indicated that no structural damage and no significant interdiffusion of elements among the layers occurred. The measured electrochemical performance data at different temperatures indicate an Arrhenius behavior or temperature activated processes. The low-porosity anode functional layer appears to be very sensitive to low hydrogen contents. The electrochemical performance is also affected by changing air flow rates.
\end{abstract}

\section{Introduction}

Solid oxide fuel cells (SOFCs) are electrochemical devices that convert directly the chemical energy of a fuel without the combustion step. It is common knowledge that they are highly efficient, fuel flexible, and modular and have cogeneration capabilities [1-4]. Significant progress in this technology has occurred over the years, including commercialization efforts; however, improvements are still possible. For instance, the oxygen electrode or cathode still limits the performance capabilities of SOFCs especially at lower temperatures $[5,6]$. One approach to improve the cathode performance is to use functional layers to improve the oxygen reduction reaction kinetics and mass transfer [7, 8]. A different approach is the use of composite cathodes where an electrolyte phase is mixed with the cathode material $[9,10]$. Others have used infiltration techniques to again enhance the oxygen reduction reaction kinetics in the cathode [11, 12]. Regardless of the approach used, chemical compatibility and long-term performance need to be better understood to ensure that SOFC systems can compete with existing technologies. In this work, we report the material and electrochemical characterization of LSCF-SDC composite cathode tested at different temperatures, hydrogen flow rates, and air flow rates. The effects of these parameters on the cell performance are discussed in detail as well as the postmortem characterization of the tested cell.

\section{Experimental}

Commercial anode-supported bilayers were purchased with a diameter of about $25.4 \mathrm{~mm}$. They consist of a highly porous $\mathrm{Ni}$-YSZ bulk support anode where a thin layer of lower porosity acts as a functional layer. A dense YSZ layer acts as the electrolyte. A commercial SDC ink is screen-printed onto the electrolyte and fired at $1240^{\circ} \mathrm{C}$ for 2 hours. The SDC layer acts as a barrier layer between YSZ and LSCF cathodes to prevent unwanted chemical reactions. A mixture of LSCFSDC is subsequently screen-printed and fired at $1110^{\circ} \mathrm{C}$ for 1 hour. Current collectors were applied on both sides with an ink and fired at $850^{\circ} \mathrm{C}$ for 1 hour. The cell active area is measured to be $2.5 \mathrm{~cm}^{2}$.

The SOFC cell was tested in the test rig shown in Figure 1. The temperature was varied between 500 and $750^{\circ} \mathrm{C}$ and closely monitored by placing a thermocouple near the cell. On the anode side, humidified hydrogen was used at room temperature with a flow rate ranging from 0.05 to 1.0 SLPM. At room temperature, the water content is around 3\% [1]. On the cathode side, air was used as an oxidant with a flow rate 


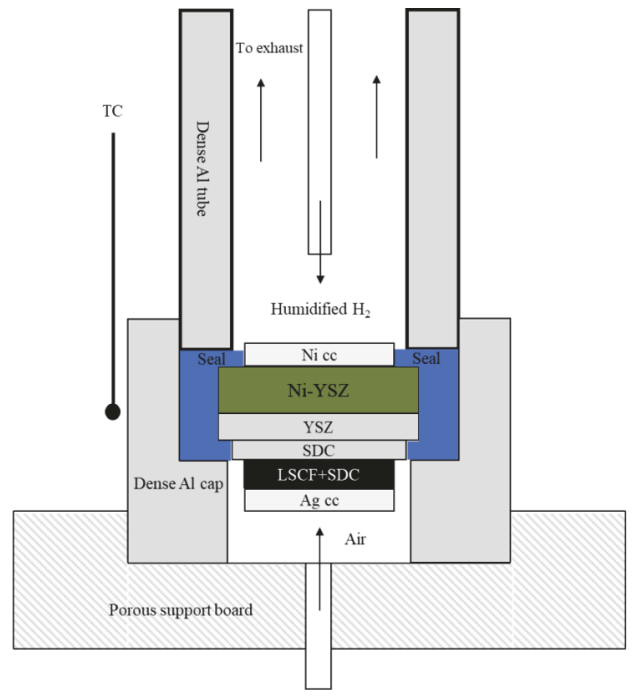

FIGURE 1: Schematics of the button cell testing setup used for this work.

ranging from 0.1 to 1.0 SLPM. Voltage-current density curves as well as impedance measurements were made using a PARSTAT 2273 apparatus coupled with a power booster obtained from AMETEK Princeton Applied Research. Voltage-current density curves were obtained at a scan rate of $3 \mathrm{mV} / \mathrm{s}$ between open-circuit voltage down to $0.3 \mathrm{~V}$. Impedance data were obtained at open-circuit voltage. The frequency range was between $0.01 \mathrm{~Hz}$ and $1 \mathrm{MHz}$ with $\mathrm{AC}$ amplitude of $10 \mathrm{mV}$ and 12 datum points per frequency decade. An analytical Quanta 200 s Environmental Scanning Electron Microscope produced by the Phillips Electron Optics company was used for the postmortem characterization for the highmagnification picture and chemical maps.

\section{Results and Discussion}

Figure 2 reports SEM pictures of the SOFC cell after the completion of all testing. The anode support layer is very porous with a thin, less porous, functional layer with a thickness of around 8 micrometers. The highly dense YSZ layer is also around 8 micrometers thick. The SDC layer is around 4 micrometers and is somewhat a dense layer. The LSCF-SDC composite cathode is highly porous and is around 20 micrometers in thickness. The SEM images show that the cell is intact and well preserved as no discernible damage or delamination of layers can be observed.

In addition to the cell structural integrity, interdiffusion of elements among all layers needs to be avoided. EDS was performed on the cross section shown in Figure 2 to obtain chemical maps. Figure 3 illustrates the chemical elements that comprise the cathode, namely, La, Sr, Co, and Fe. La is uniformly distributed in the cathode, and the sharp line near the SDC layer would indicate negligible diffusion into the barrier layer. La is one of the most abundant elements in the cathode, Fe being the other one. The SEM was not able to detect $\mathrm{Sr}$ in meaningful quantities. This was mostly because X-ray lines overlap between Sr and Y. In addition, the amount of $\mathrm{Sr}$ in the cathode is not very large and, in general, SEM machines do not have a very high resolution. Co is also present in small amounts, and it is reasonably well distributed within the cathode. Again, within the SEM resolution, Co did not move into the barrier layer either. Lastly, Fe is uniformly distributed in the cathode; however, small amounts are present in the SDC layer. Iron is used as a sintering aid to obtain dense ceria layers, and some commercial suppliers will add small amounts of iron oxide in the SDC ink [13]. Because of this, it is hard to distinguish if iron has migrated from the cathode to the SDC layer as some of it is already there.

Figure 4 shows the chemical maps for Sm and Ce. Both elements are uniformly distributed within the SDC layer, and as expected it extends uniformly into the composite cathode. Neither element has migrated into the YSZ electrolyte as sharp edges can be clearly observed. Noticeable is some background noise in the Sm map, but none is observed with the Ce map. Figure 5 reports the chemical maps for $\mathrm{Y}, \mathrm{Zr}$, and Ni. Y and $\mathrm{Zr}$ are uniformly observed in the electrolyte layer. The sharp edge near the SDC layer indicates no interdiffusion with the barrier layer. $\mathrm{Y}$ and $\mathrm{Zr}$ are, however, not uniformly distributed in the anode. The anode functional contains more $\mathrm{Y}$ and $\mathrm{Zr}$ than the bulk anode in order to increase the three-phase boundary, thereby increasing the electrochemical reactions in the fuel side [14]. Ni is uniformly distributed in bulk anode in order to increase electrical conductivity, but less $\mathrm{Ni}$ is present in the anode functional layer where a mixed conductivity is desired [15].

Interdiffusion between SDC and YSZ layer has been recently reported for SOFC cells fired at $1400^{\circ} \mathrm{C}$ and occurs at firing temperatures above $1200^{\circ} \mathrm{C}$ [16]. Similar behavior has been reported for a ceria barrier layer doped with gadolinium as well [17]. For SDC/YSZ bilayers where the SDC layer is deposited, using a Pulsed Laser Deposition technique avoids the high temperature firing step, and the interdiffusion between the two layers has not been observed [18]. Additional studies report that the dissolution of Sm into the YSZ phase can also result in decreased ionic conductivity in the electrolyte $[19,20]$. The reason that interdiffusion between SDC and YSZ layer is not observed in the tested cell is likely due to the low firing temperature of the SDC layer $\left(1240^{\circ} \mathrm{C}\right)$. Though interdiffusion may have not been completely prevented, the effects are very small and cannot be detected using conventional SEM/EDS techniques.

Figure 6 presents the voltage-current density characteristics of the tested cell measured from 500 to $750^{\circ} \mathrm{C}$ at $50^{\circ} \mathrm{C}$ intervals. The cell power density increases with temperature and reaches a maximum of about $1.2 \mathrm{~W} / \mathrm{cm}^{2}$. The cell opencircuit voltage at $750^{\circ} \mathrm{C}$ is around $1.1 \mathrm{~V}$ which is slightly lower than the Nernst voltage of $1.110 \mathrm{~V}$ at the same temperature [15]. This slight difference is due to minor leakages through the seal in the setup. As it can be seen, the cell performance at $750^{\circ} \mathrm{C}$ is quite good but becomes irrelevant as the temperature reaches $500^{\circ} \mathrm{C}$. At high current densities, the voltage does not drop rapidly which suggests that diffusion losses are not very large at all temperatures. 

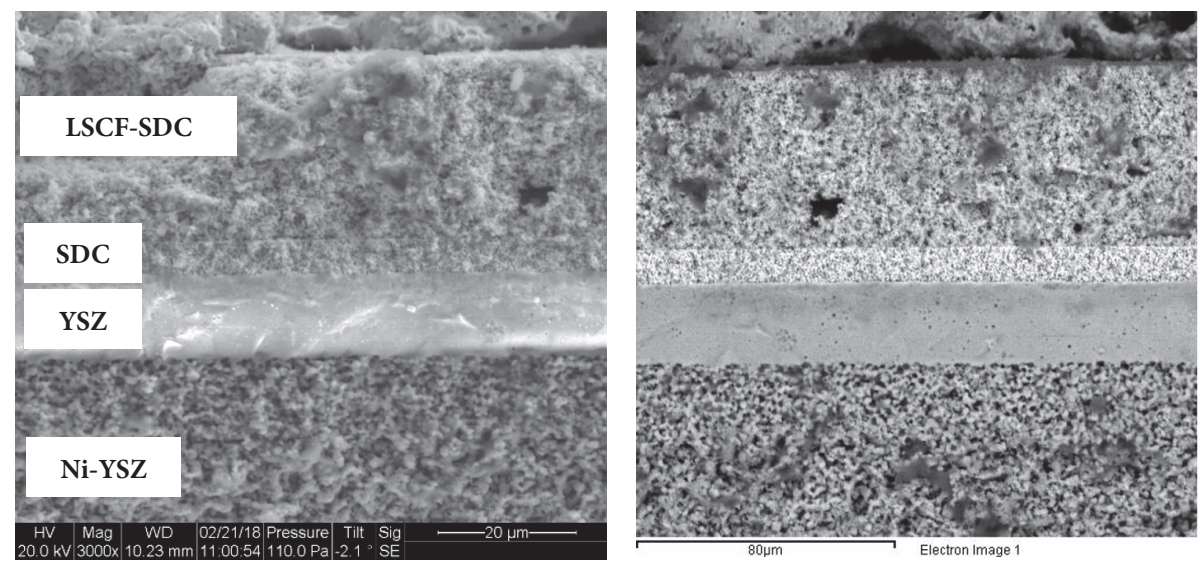

FIGURE 2: SEM cross section images of the tested SOFC cell.

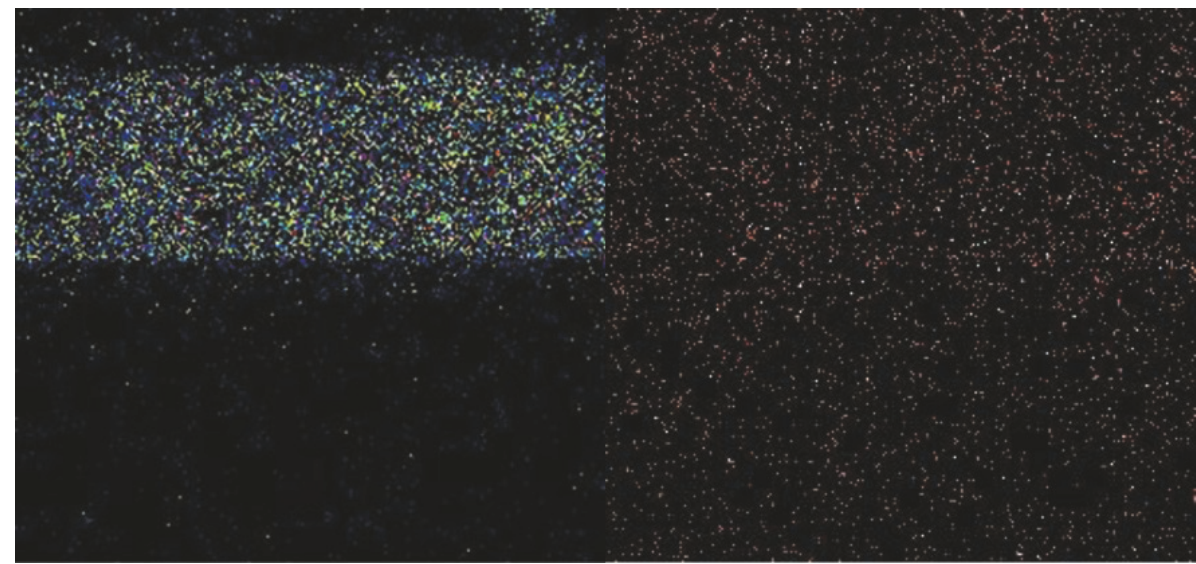

La Lal

Sr Kal

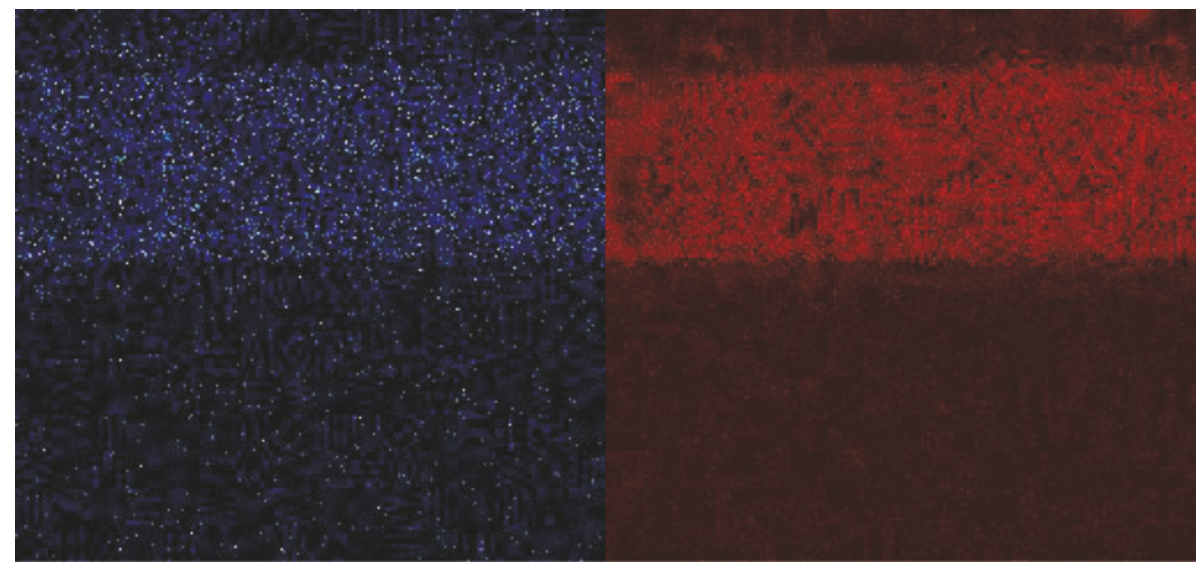

Co Ka1

Fe Ka1

Figure 3: EDS chemical maps for La, Sr, Co, and Fe elements.

Impedance data at OCV were collected at the same temperatures, and the Nyquist plots are shown in Figure 7. The data show that the performance decline is mostly due to electrode polarization because the low frequency intercept becomes larger and larger as temperature decreases. In other words, the cathode electrochemical activity or capability is severely diminished with lowering temperatures. The ohmic portion of the cell can be found from the high frequency intercept. The ohmic contribution to the lowered cell performance is smaller than the electrode polarization; however, a significant increase in ohmic resistance is still present. See inset in Figure 7. To further demonstrate the above, Table 1 reports the ohmic resistance and total electrodes polarization estimated from the impedance data shown in Figure 7. At 


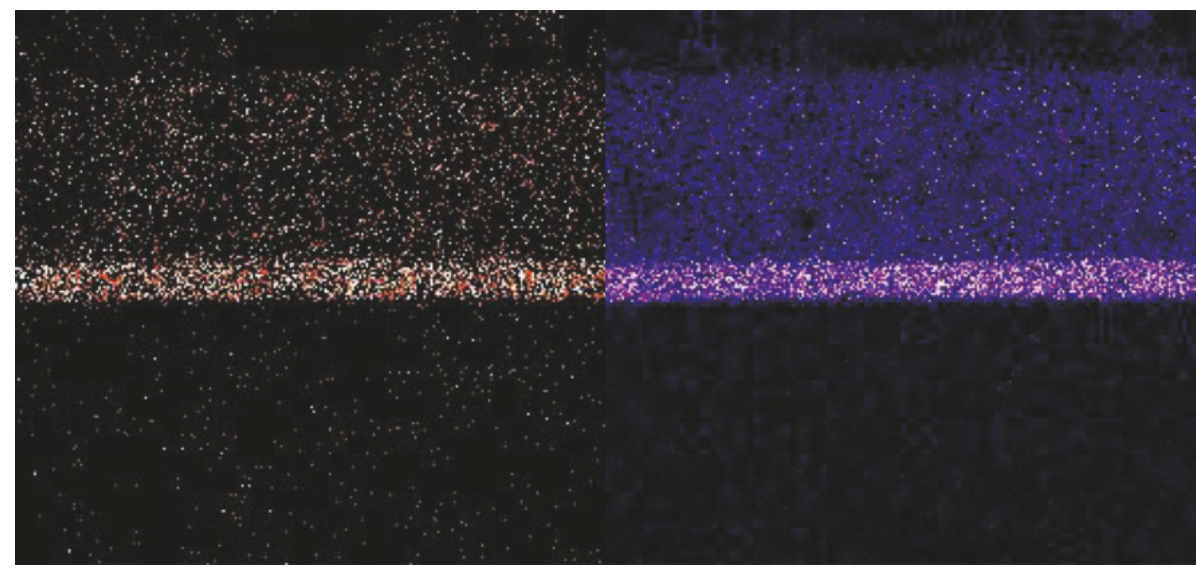

Sm La1

Ce Lal

FIgURE 4: EDS chemical maps for Sm and Ce elements.
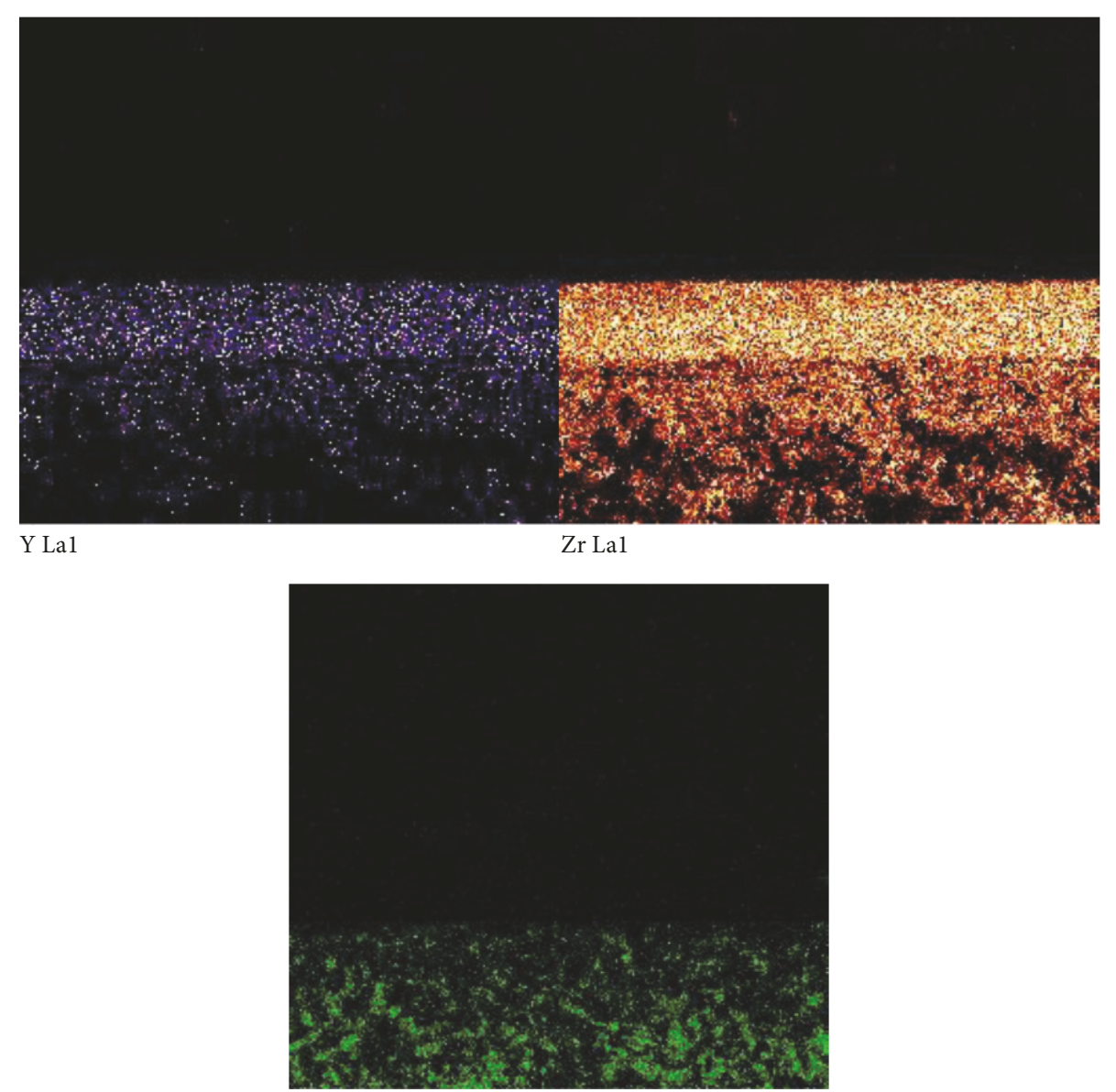

Ni Kal

FIGURE 5: EDS chemical maps for $\mathrm{Y}, \mathrm{Zr}$, and Ni elements.

each temperature, the percentage ohmic contribution to the total resistance is much smaller. Also noticeable is that both resistances are temperature activated processes, and they follow an Arrhenius behavior. This is shown in Figure 8 where the logarithm of both resistances is plotted against the inverse of temperature. The observed linear behavior of the data confirms the Arrhenius behavior.

To further characterize the cell performance, the hydrogen flow rate was varied from 0.05 to 1.0 standard liters per minute at $750^{\circ} \mathrm{C}$. The voltage-current density characteristics 


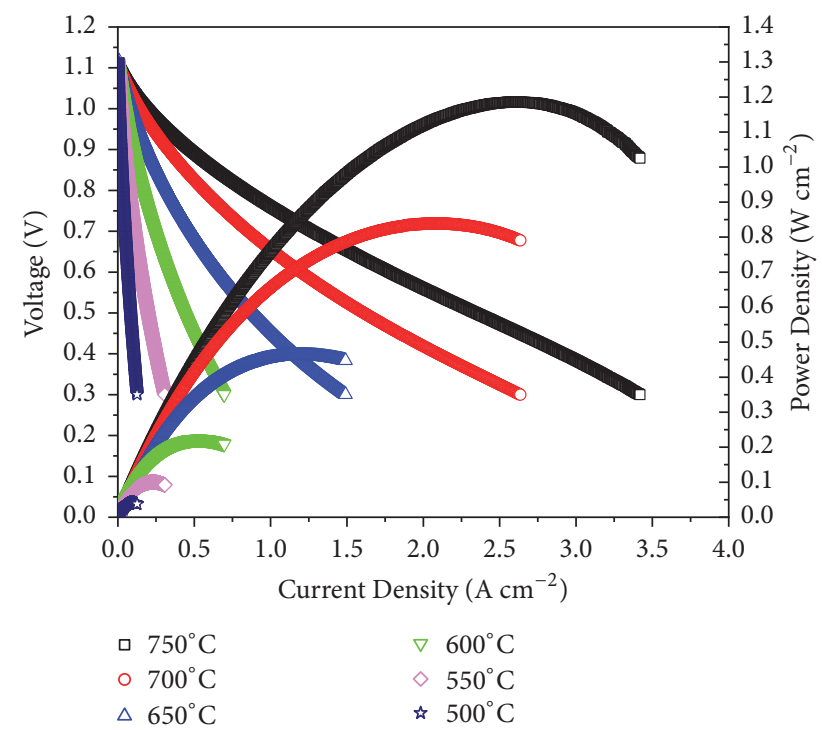

FIGURE 6: Voltage and power density curves versus current density at different temperatures.

TABLE 1: Ohmic resistance and electrodes polarization estimated from the impedance data shown in Figure 7.

\begin{tabular}{ccccc}
\hline$T\left({ }^{\circ} \mathrm{C}\right)$ & $\begin{array}{c}\text { Ohmic Resistance } \\
\left(\mathrm{ohm} \mathrm{cm}^{2}\right)\end{array}$ & $\begin{array}{c}\text { Electrodes } \\
\text { Polarization } \\
\left(\mathrm{ohm} \mathrm{cm}^{2}\right)\end{array}$ & $\begin{array}{c}\text { Percent } \\
\text { Ohmic }\end{array}$ & $\begin{array}{c}\text { Percent } \\
\text { Polarization }\end{array}$ \\
\hline 500 & 1.5 & 17 & $8 \%$ & $92 \%$ \\
550 & 1.0 & 6.5 & $13 \%$ & $87 \%$ \\
600 & 0.6 & 3.1 & $16 \%$ & $84 \%$ \\
650 & 0.4 & 1.9 & $17 \%$ & $83 \%$ \\
700 & 0.2 & 1.2 & $14 \%$ & $86 \%$ \\
750 & 0.1 & 0.8 & $11 \%$ & $89 \%$ \\
\hline
\end{tabular}

are shown in Figure 9. The cell performance is not affected at large flow rates or between 1 and 0.5 SLPM. At 0.25 SLPM, the cell performance starts to be affected at high current densities. Some small data oscillation is also observed for this set of data. Further decrease in the hydrogen flow rate affects the performance sooner and sooner (or at lower current densities). The data oscillation also becomes more evident and significant. To the authors' knowledge, this behavior has not been reported in the literature. However, this could be a significant finding as it indicates that the low-porosity anode functional layer may affect how fast hydrogen may diffuse (or water diffuses out) through the three-phase boundary especially at lower hydrogen concentrations. This behavior could be a concern in a stack operating at high fuel utilization in locations where the hydrogen concentration becomes low and the water concentration becomes high. For this set of tests, the impedance data collected at $\mathrm{OCV}$ are shown in Figure 10. The ohmic portion or high frequency intercepts do not change with changing hydrogen flow rate as expected. Except for the lowest two flow rates, the low frequency intercepts are reasonably the same. This behavior indicates

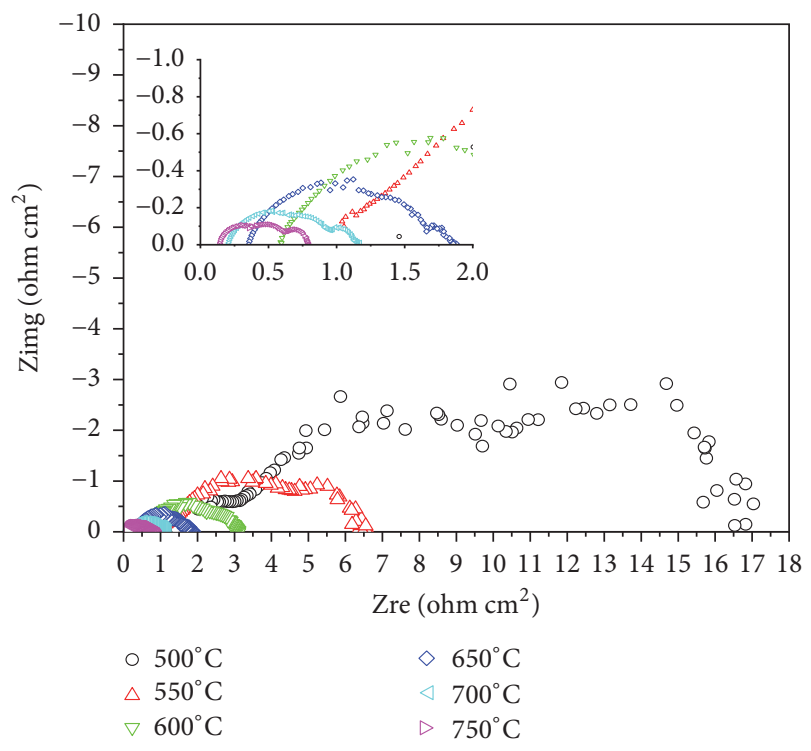

FIGURE 7: Impedance curves at different temperatures.

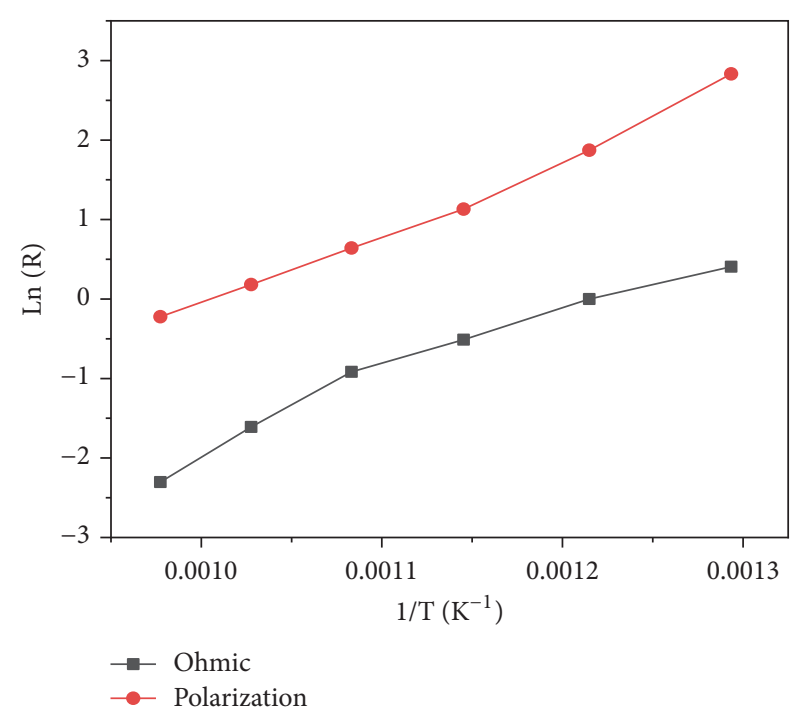

FIGURE 8: Logarithm of resistances as a function of the inverse temperature.

that the circles at low frequency are related to diffusion processes.

Finally, the dependence on air flow rate was also studied. Figure 11 presents the voltage-current density characteristics for an air flow rate between 0.1 and 1.0 SLPM at $750^{\circ} \mathrm{C}$. The curves are affected at all flow rates, though the loss of performance is larger at the lowest flow rates. For this set of tests, the impedance data collected at OCV are shown in Figure 12. Again, the ohmic portion does not change with changing flow rates. However, the low frequency circles do not seem to increase significantly and do not capture very well what is observed with the voltage-current density curves. 


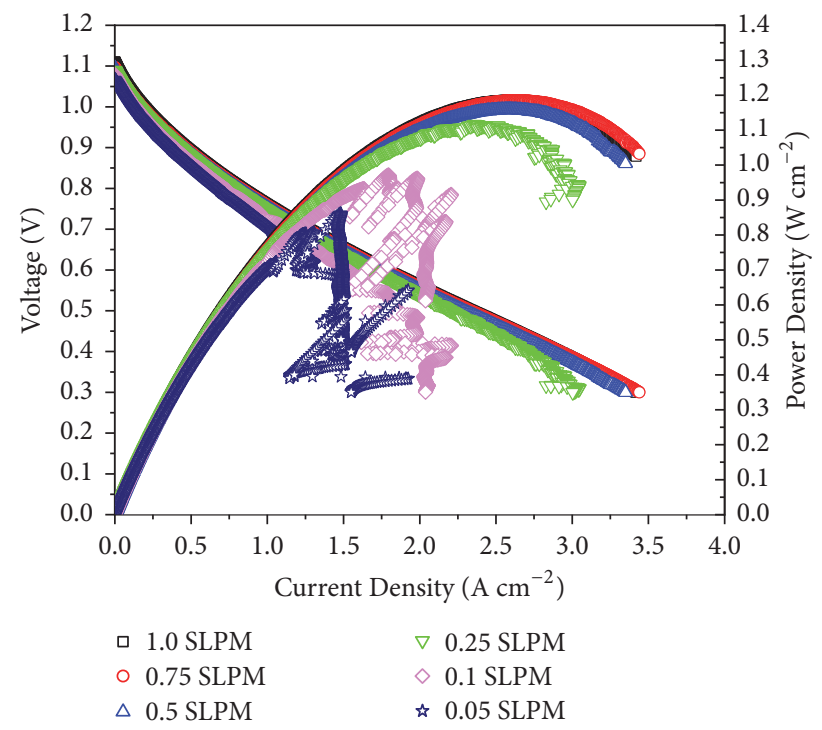

FIGURE 9: Voltage and power density curves versus current density at different hydrogen flow rates at $750^{\circ} \mathrm{C}$.

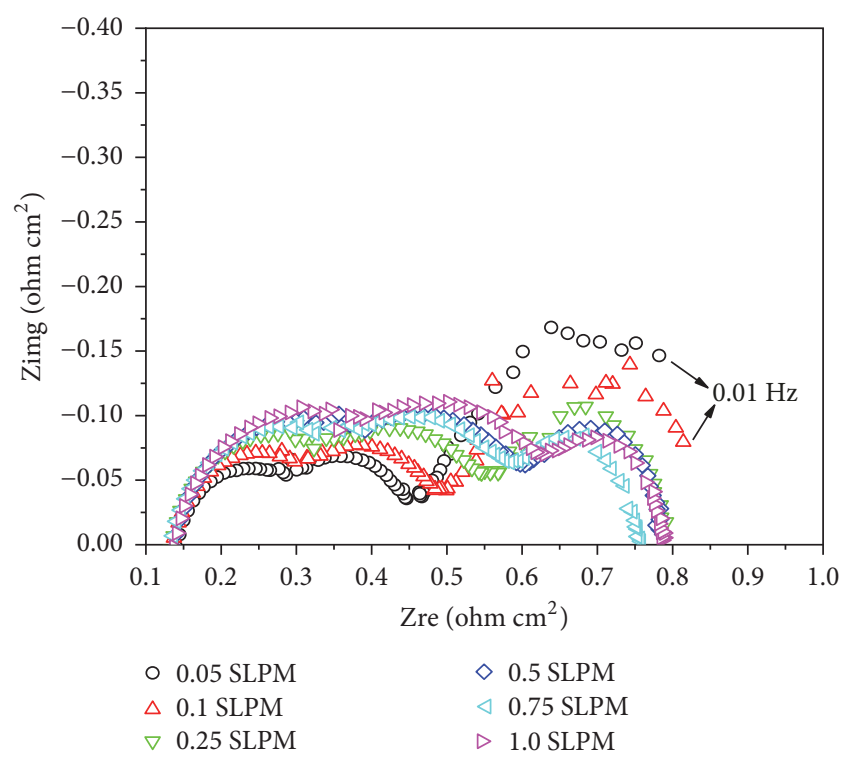

FIGURE 10: Impedance curves at different hydrogen flow rates at $750^{\circ} \mathrm{C}$.

\section{Conclusion}

In this work, an anode-supported SOFC cell has been tested and characterized at different temperatures and reactant flow rates. SEM/EDS analysis indicates no significant interdiffusion of the elements has occurred. In addition, the tested cell preserved its structural integrity and shows no damage or delamination. Voltage-current density and impedance data at different temperatures indicate an Arrhenius behavior or temperature activated processes. Variation in hydrogen flow rates indicates concerns with the low-porosity anode functional layer especially at low hydrogen contents. Variation in air flow rates also lowers the cell performance.

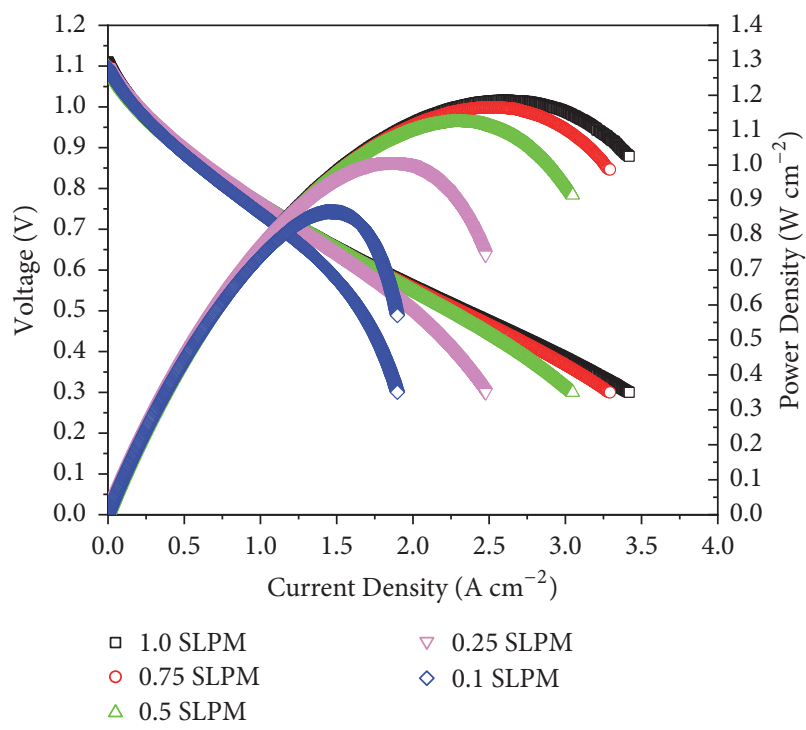

FIGURE 11: Voltage and power density curves versus current density at different air flow rates at $750^{\circ} \mathrm{C}$.

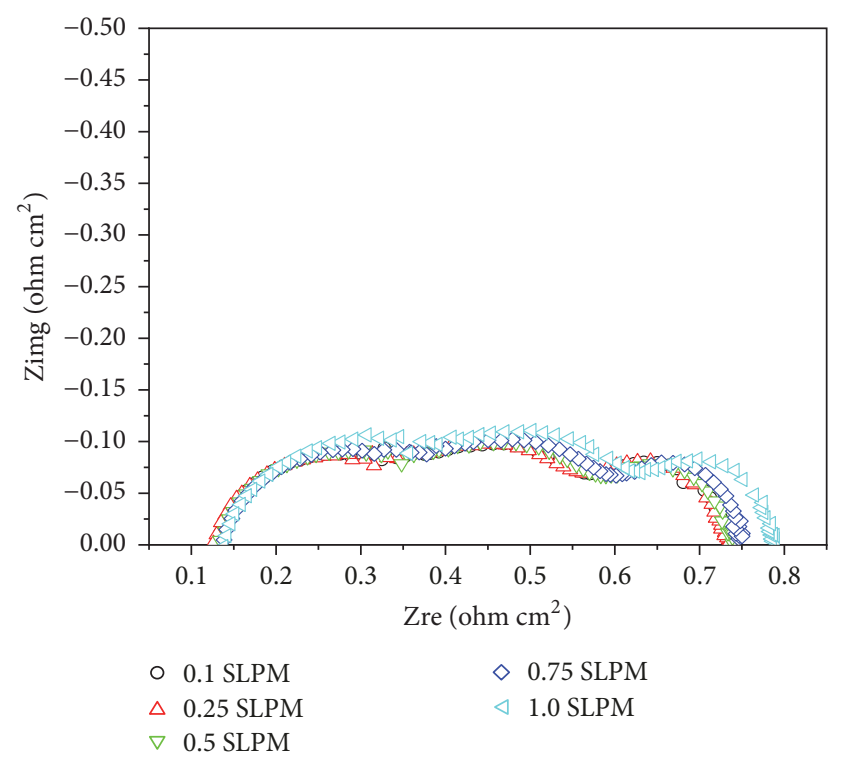

Figure 12: Impedance curves at different air flow rates at $750^{\circ} \mathrm{C}$.

\section{Nomenclature}

LSCF: Lanthanum strontium cobalt ferrite

SOFCs: Solid oxide fuel cells

Ni: Nickel

YSZ: Yttria stabilized zirconia

SDC: Samaria doped zirconia

SEM: Scanning electron microscope

EDS: Energy dispersive spectroscopy

OCV: Open-circuit voltage

SLPM: Standard liters per minute

$\mathrm{Al} \quad$ Alumina or aluminum oxide. 


\section{Data Availability}

The data used to support the findings of this study are available from the corresponding author upon request.

\section{Conflicts of Interest}

The authors declare that they have no conflicts of interest.

\section{Acknowledgments}

The work presented in this paper was partially supported by the Department of Energy (DOE) through the National Energy Technology Laboratory (NETL) under Award no. DEFE0026168. Special thanks are due to Robert Cunningham for collecting the SEM pictures and EDS chemical maps.

\section{References}

[1] N. Q. Minh, "Solid oxide fuel cell technology - Features and applications," Solid State Ionics, vol. 174, no. 1-4, pp. 271-277, 2004.

[2] M. Liu, M. E. Lynch, K. Blinn, F. M. Alamgir, and Y. Choi, "Rational SOFC material design: New advances and tools," Materials Today, vol. 14, no. 11, pp. 534-546, 2011.

[3] Z. Zhan and S. A. Barnett, "An octane-fueled solid oxide fuel cell," Science, vol. 308, no. 5723, pp. 844-847, 2005.

[4] M. Liu, Y. Choi, L. Yang et al., "Direct octane fuel cells: A promising power for transportation," Nano Energy, vol. 1, no. 3, pp. 448-455, 2012.

[5] S. B. Adler, "Mechanism and kinetics of oxygen reduction on porous Lal-xSrxCoO3- $\delta$ electrodes," Solid State Ionics, vol. 111, no. 1-2, pp. 125-134, 1998.

[6] L. Nie, Z. Liu, M. Liu, L. Yang, Y. Zhang, and M. Liu, “Enhanced Performance of La ," Journal of Electrochemical Science and Technology, vol. 1, no. 1, pp. 50-56, 2010.

[7] N. T. Hart, N. P. Brandon, M. J. Day, and N. Lapeña-Rey, "Functionally graded composite cathodes for solid oxide fuel cells," Journal of Power Sources, vol. 106, no. 1-2, pp. 42-50, 2002.

[8] S. Zha, Y. Zhang, and M. Liu, "Functionally graded cathodes fabricated by sol-gel/slurry coating for honeycomb SOFCs," Solid State Ionics, vol. 176, no. 1-2, pp. 25-31, 2005.

[9] Z. Shao and S. M. Haile, "A high-performance cathode for the next generation of solid-oxide fuel cells," Nature, vol. 431, pp. 170-173, 2004.

[10] C. Fu, K. Sun, N. Zhang, X. Chen, and D. Zhou, "Electrochemical characteristics of LSCF-SDC composite cathode for intermediate temperature SOFC," Electrochimica Acta, vol. 52, no. 13, pp. 4589-4594, 2007.

[11] M. Shah, P. W. Voorhees, and S. A. Barnett, “Time-dependent performance changes in LSCF-infiltrated SOFC cathodes: The role of nano-particle coarsening," Solid State Ionics, vol. 187, no. 1, pp. 64-67, 2011.

[12] D. Ding, X. Li, S. Y. Lai, K. Gerdes, and M. Liu, "Enhancing SOFC cathode performance by surface modification through infiltration," Energy \& Environmental Science, vol. 7, no. 2, pp. 552-575, 2014.

[13] T. S. Zhang, J. Ma, L. B. Kong, S. H. Chan, P. Hing, and J. A. Kilner, "Iron oxide as an effective sintering aid and a grain boundary scavenger for ceria-based electrolytes," Solid State Ionics, vol. 167, no. 1-2, pp. 203-207, 2004.
[14] N. Mahato, A. Banerjee, A. Gupta, S. Omar, and K. Balani, "Progress in material selection for solid oxide fuel cell technology: A review," Progress in Materials Science, vol. 72, pp. 141-337, 2015.

[15] S. C. Singhal, "Solid oxide fuel cells for stationary, mobile, and military applications," Solid State Ionics, vol. 152-153, pp. 405410, 2002.

[16] Z. Wang, X. Huang, Z. Lv et al., "Preparation and performance of solid oxide fuel cells with YSZ/SDC bilayer electrolyte," Ceramics International, vol. 41, no. 3, pp. 4410-4415, 2015.

[17] G. Constantin, C. Rossignol, J.-P. Barnes, and E. Djurado, "Interface stability of thin, dense CGO film coating on YSZ for solid oxide fuel cells," Solid State Ionics, vol. 235, pp. 36-41, 2013.

[18] J. Qian, Z. Tao, J. Xiao, G. Jiang, and W. Liu, "Performance improvement of ceria-based solid oxide fuel cells with yttriastabilized zirconia as an electronic blocking layer by pulsed laser deposition," International Journal of Hydrogen Energy, vol. 38, no. 5, pp. 2407-2412, 2013.

[19] T. Matsui, M. Komoto, H. Muroyama, K. Kishida, H. Inui, and K. Eguchi, "Degradation factors in $(\mathrm{La}, \mathrm{Sr})(\mathrm{Co}, \mathrm{Fe}) \mathrm{O}_{3-\delta}$ cathode/ $\mathrm{Sm}_{2} \mathrm{O}_{3}-\mathrm{CeO}_{2}$ interlayer $/ \mathrm{Y}_{2} \mathrm{O}_{3}-\mathrm{ZrO}_{2}$ electrolyte system during operation of solid oxide fuel cells," Journal of Power Sources, vol. 312, pp. 80-85, 2016.

[20] T. Matsui, S. Li, H. Muroyama, K. Kishida, H. Inui, and K. Eguchi, "Electrochemical property of solid solutions formed in $(\mathrm{La}, \mathrm{Sr})(\mathrm{Co}, \mathrm{Fe}) \mathrm{O}_{3-\delta}$ cathode/doped $-\mathrm{CeO}_{2}$ interlayer $/ \mathrm{Y}_{2} \mathrm{O}_{3}-$ $\mathrm{ZrO}_{2}$ electrolyte system during operation of solid oxide fuel cells," Solid State Ionics, vol. 300, pp. 135-139, 2017. 

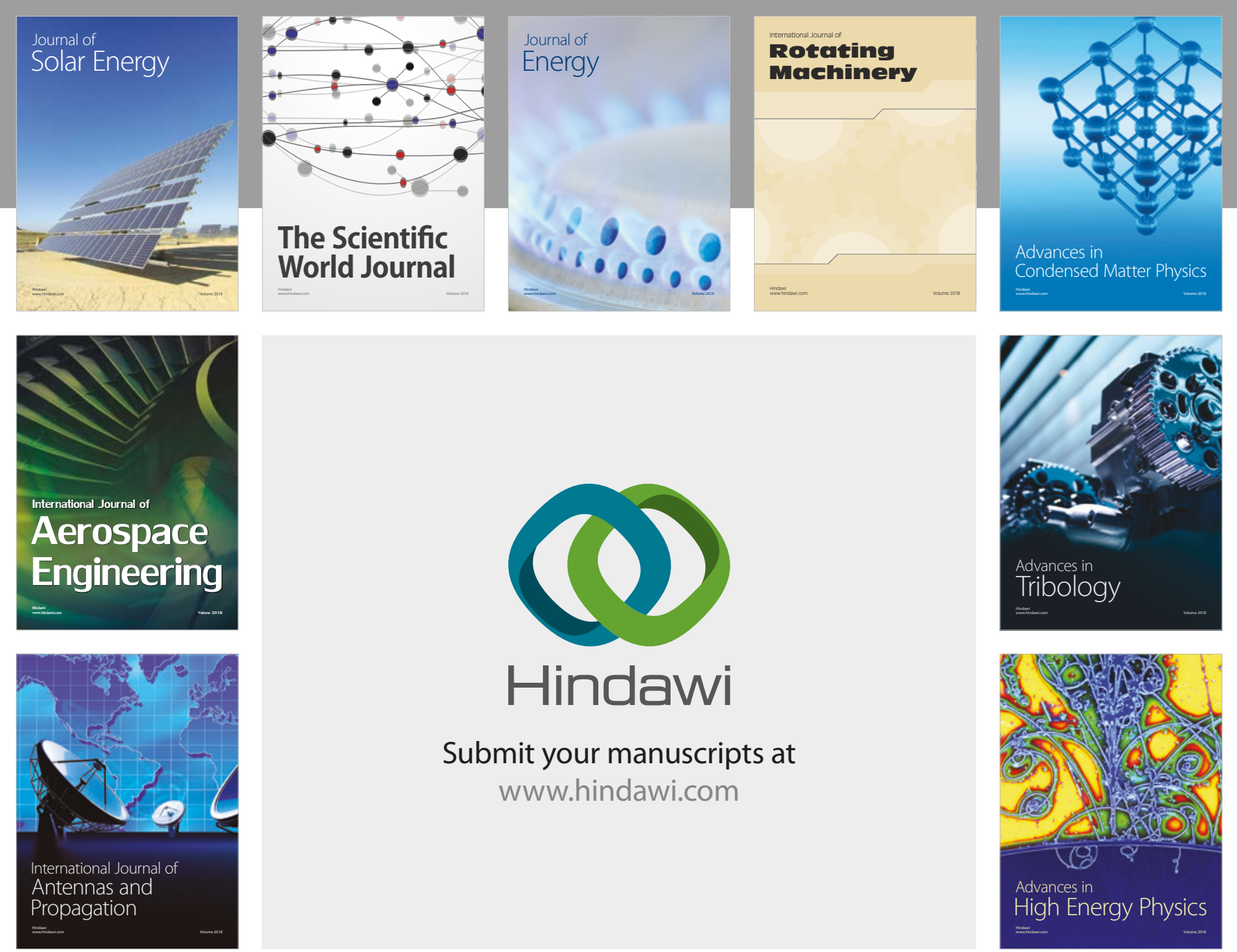

Submit your manuscripts at

www.hindawi.com
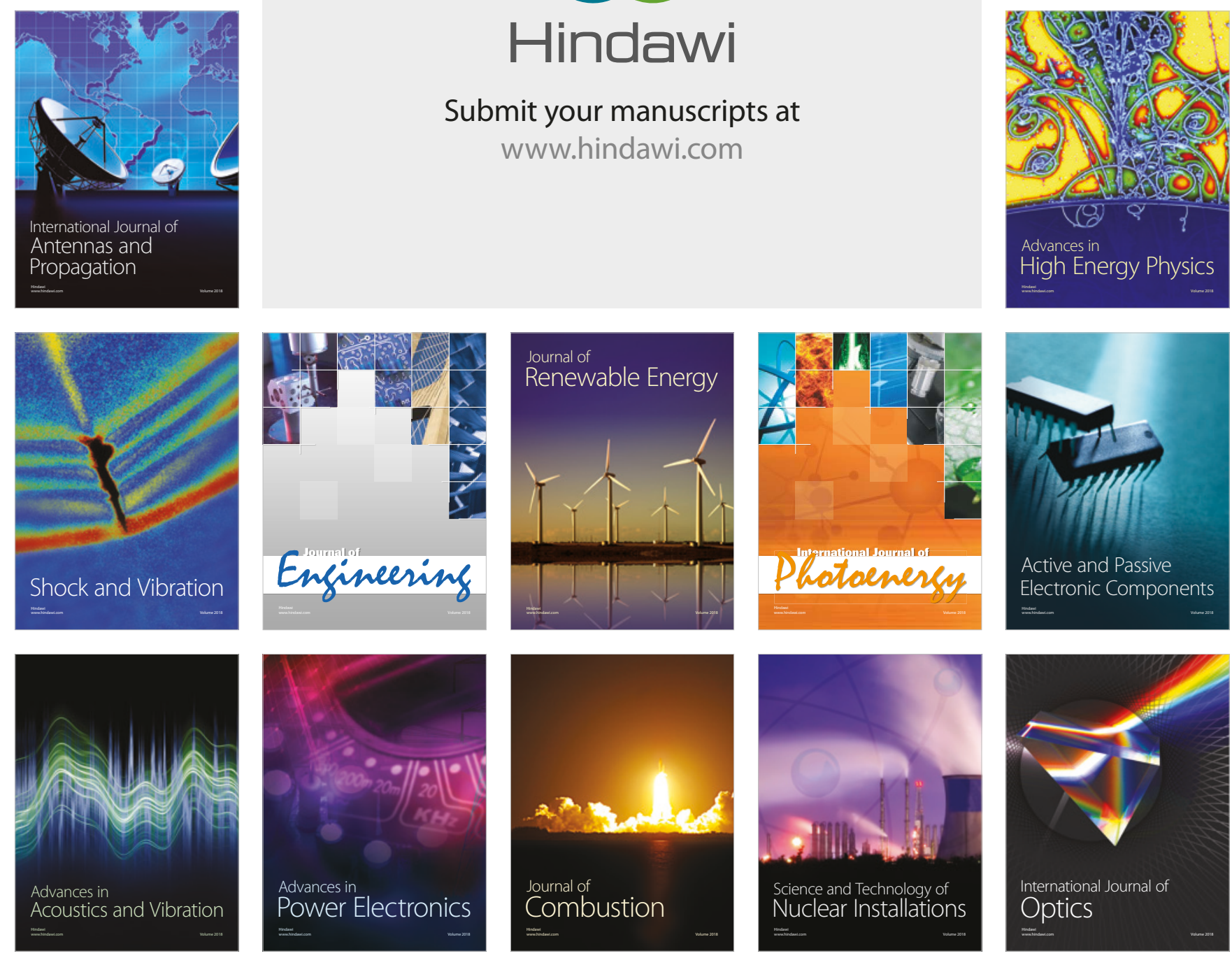